\title{
Changes in selected biochemical parameters (including FGF21) during subclinical and clinical ketosis in dairy cows
}

\author{
YUANYUAN CHEN, ZHIHAO DONG, RUIRUI LI, CHUANG XU \\ College of Animal Science and Veterinary Medicine, Heilongjiang Bayi Agricultural University, \\ Daqing High-tech Industrial Development Zone, Daqing 163319, PR China
}

Chen Y., Dong Z., Li R., Xu C.

Changes in selected biochemical parameters (including FGF21) during subclinical and clinical ketosis
in dairy cows

Summary

Negative energy balance (NEB) is a common pathological cause of ketosis. As the major organs of lipid metabolism, the liver and fat tissue take part in regulating lipid oxidative capacity and energy demands, which is also a key metabolic pathway that regulates NEB development during the perinatal period. Fibroblast Growth Factor 21 (FGF21) is a novel metabolic regulator involved in the control of fatty acid oxidation and lipid metabolism during a prolonged negative energy balance. Our study determined a correlation between serum FGF21 and $\beta$-hydroxybutyric acid (BHBA) levels in dairy cows with ketosis. We used sixty cows with low milk yield, abnormal glucose metabolism, and ketosis. Serum FGF21 and BHBA levels were measured using commercial kits. Serum FGF21 increased with increasing BHBA levels up to $1.6 \mathrm{mmol} / \mathrm{L}$. At BHBA levels $>1.6 \mathrm{mmol} / \mathrm{L}$, FGF21 decreased. Serum FGF21 levels were positively associated with BHBA levels, particularly in dairy cows with subclinical ketosis $(r=0.647, \mathrm{P}<0.01)$. At $\mathrm{BHBA}$ levels between $1.2 \mathrm{mmol} / \mathrm{L}$ and $1.6 \mathrm{mmol} / \mathrm{L}$, FGF21 was more closely correlated with BHBA than with other metabolic parameters. At BHBA levels $>1.6 \mathrm{mmol} / \mathrm{L}$, the association between FGF21 and BHBA was not significant. In conclusion, our results show that FGF21 was closely related with SK in cows. FGF21 may be a promising regulator in the prevention of subclinical ketosis.

Keywords: $\beta$-hydroxybutyric acid, dairy cows, fibroblast growth factor 21, subclinical ketosis

Ketosis may result from a negative energy balance (NEB) in dairy cows during the perinatal period. The disease may cause significant economic losses, especially for the dairy industry (1). The perinatal period is very important for the health status and growth performance of dairy cows. Postpartum dairy cows are often in a state of NEB induced by decreased energy intake and increased energy demands, which contribute to ketosis $(5,16)$. Disorders in gluconeogenesis, lipid mobilization, and hepatic lipid transport may be involved in the pathogenesis of ketosis $(9,14,15)$.

Fibroblast Growth Factor 21 (FGF21) is a novel metabolic regulator involved in the control of fatty acid oxidation and lipid metabolism during a prolonged negative energy balance $(7,13)$. Recent studies have shown that therapeutic administration of FGF21 normalizes blood glucose and triglyceride levels in ob/ $\mathrm{ob}$ and $\mathrm{db} / \mathrm{db}$ mice and protect them from diabetes. FGF21-transgenic mice are viable and resistant to diet-induced obesity (11). Additionally, FGF21-treated animals have increased energy expenditure, fat utilization, and lipid excretion (4). In patients with type 2 diabetes mellitus, FGF21 serum levels dramatically increase and may play a role in the pathogenesis of the disease (3). Mice lacking FGF21 have disorders in gluconeogenesis and ketogenesis (18). In addition, FGF21 injections may reduce insulin and free fatty acid levels in blood (6). Prolonged fasting induces hepatic FGF21 gene expression in mice (12). FGF21, in turn, stimulates hepatic gluconeogenesis, fatty acid oxidation, and ketogenesis.

NEB initiates fat mobilization and a subsequent increase in the blood concentration of non-esterified fatty acids (NEFAs) and $\beta$-hydroxybutyrate (BHBA). The diagnostic criterion for subclinical ketosis is based on serum/plasma BHBA levels. BHBA kits are commercially available and can be measured in an automatic biochemical analyzer. Studies suggest that 
serum $\mathrm{BHBA}>1.60 \mathrm{mmol} / \mathrm{L}$ is indicative of clinical ketosis in cows. When BHBA levels are 1.20 to 1.60 $\mathrm{mmol} / \mathrm{L}$, dairy cows are considered to have subclinical ketosis. Even though serum levels of BHBA are a diagnostic criterion, routine testing for early diagnosis is expensive and inconvenient. Therefore, it is urgent to develop a convenient and cost-effective reagent kit. Dairy cows display a series of physiological changes during the perinatal period and have a different nutrient metabolism during the physiological stages of the perinatal period. Blood biochemical indicators may predict certain metabolic diseases, such as fatty liver, ketosis, and hypocalcemia. Body condition score, glucose, NEFA, and BHBA are considered the most reliable indicators of herd disease (ketosis and hypocalcemia). On the other hand, some indicators have not been used for predicting ketosis. These indicators include indicators of glucose metabolism, lipid metabolism, serum enzymes, hormones, and protein metabolism, which partly reflect glucose, fat, protein, and lipid metabolism in dairy cows with metabolic diseases (e.g., ketosis, fatty liver, and hypocalcemia) during the perinatal period. These indicators may become potential markers in the early diagnosis and prevention of metabolic diseases in cows. For example, hepatocyte enzyme indicators, AST, and glutamic dehydrogenase can be used to monitor liver steatosis in dairy cows during postpartum. More novel indicators related with metabolic diseases have been discovered. In addition, some studies report that indicators of inflammation (e.g., TNF- $\alpha$ and adiponectin) $(10,17)$ and oxidative stress (CYP450) can be used to predict metabolic disease. However, most serum markers used for predicting metabolic disease are limited by small sample sizes. FGF21 is a hormonelike cytokine secreted mainly by the liver that plays important roles in lipid metabolism. Researchers have found that there is a close relationship between FGF21 and steatosis degeneration, but the clinical significance of FGF21 in predicting ketosis and whether it can be used as a serum marker are still unknown. The study analyzed the relationship between FGF21 and blood parameters in dairy cows with ketosis.

\section{Material and methods}

Animals. A number of young cattle as well as dry and lactating dairy cows $(n=2160)$ were from commercial dairy herds in northeastern China (MiShan, Heilongjiang, China). The animals used in the present study were parity 2-4 Holstein cows with similar milk production and partum time $(\mathrm{n}=90)$. Cows with serum BHBA levels $>1.60 \mathrm{mmol} / \mathrm{L}$ and significant clinical symptoms were diagnosed with clinical ketosis (CK), cows with serum BHBA levels $>1.20 \mathrm{mmol} / \mathrm{L}$ had subclinical ketosis (SK), and animals with serum BHBA levels $<1.20 \mathrm{mmol} / \mathrm{L}$ and no clinical symptoms were considered normal controls (NC). Among the 90 cows, 35 had CK, 25 had SK, and 30 were healthy. These animals did not have drug-induced liver diseases, pregnancy, fever, mastitis, or metritis. The 90 cows were divided into three groups:
30 healthy cows were group $1(\mathrm{Q}), 35$ cows with CK were group 2 (Q2), and 25 cows with SK were group 3 (Q3). All cows in this study were fed a total mixed ration (TMR) three times a day: at 05:00, 14:00, and 20:00. The TMR consisted of $55.60 \%$ dry matter (DM), $16.00 \%$ crude protein, $34.30 \%$ neutral detergent fiber, $22.00 \%$ acid detergent fiber, $5.60 \%$ fat, $1.07 \%$ calcium, $0.49 \%$ phosphorus, $0.32 \%$ magnesium, $0.13 \%$ sodium, $1.40 \%$ potassium, $0.39 \%$ chloride, and $0.22 \%$ sulfur. All cows were kept in a semi-open cowshed.

Serum preparation. Total blood was collected on days 15-30 postpartum. The cows were restricted manually, and blood samples were collected from the vena caudalis into tubes without anticoagulant prior to the early morning feeding. Then the blood samples were transferred to the laboratory in an icebox within an hour. Following a 30-minute incubation at room temperature, the blood samples were centrifuged at $3,000 \times \mathrm{g}$ for $30 \mathrm{~min}$. The sera were stored at $-20^{\circ} \mathrm{C}$ until utilization.

Measurement of serum FGF21. FGF21 concentrations were measured using an RD Bovine FGF21 commercial ELISA (R\&D Systems Inc. Minneapolis, MN, USA) in an automatic biochemistry analyzer (Jiancheng, Nanjing, China).

Measurements of biochemical parameters. Glucagon (GC) was measured by RD Bovine Glucagon ELISA, growth hormone $(\mathrm{GH})$ was determined by RD Bovine Growth hormone ELISA, acetoacetate (AcAc) was assessed by RD Bovine Acetoacetate ELISA, and insulin (INS) was determined by RD Bovine INS ELISA. All biochemical parameters were analyzed with a Huadong electronic DG5033A microplate reader (Huadong, Nanjing, China). Serum levels of triglycerides (TG), alanine aminotransferase (ALT), glycerin (GI), non-esterified fatty acids (NEFAs), creatine kinase (CKN), aspartate aminotransferase (AST), and blood glucose (GLU) were measured with a Beckman Synchron CX5CE analyzer (Beckman Coulter, Inc., Fullerton, CA, USA). The 90 cows were assigned to three groups according to serum BHBA levels.

The cows with high plasma BHBA levels were older animals. Among the cows, there were no significant differences in most of the serum biochemical parameters, except for NEFA and AST levels, which increased with increasing BHBA levels $(\mathrm{P}<0.01)$. NEFA levels were $553.99 \pm 285.05$ $\mu \mathrm{mol} / \mathrm{L}, 1034.89 \pm 433.75 \mu \mathrm{mol} / \mathrm{L}$, and $1186.33 \pm 608.18$ $\mu \mathrm{mol} / \mathrm{L}$ in $\mathrm{Q} 1, \mathrm{Q} 2$, and $\mathrm{Q} 3$, respectively. AST increased with a gradual increase in serum BHBA levels $(\mathrm{P}=0.001)$, with the highest level of $65.44 \pm 54.38 \mathrm{mmol} / \mathrm{L}$ in Q2 and the lowest level of $19.01 \pm 14.04 \mathrm{mmol} / \mathrm{L}$ in Q3. Serum TG, $\mathrm{CKN}$, and INS levels decreased gradually with increasing BHBA levels $(\mathrm{P}<0.05)$. In Q1, Q2, and Q3, TG levels were $0.10 \pm 0.02 \mathrm{mmol} / \mathrm{L}, 0.09 \pm 0.01 \mathrm{mmol} / \mathrm{L}$, and $0.08 \pm 0.16$ $\mathrm{mmol} / \mathrm{L}$, respectively; CKN levels were $1.48 \pm 0.76 \mathrm{U} / \mathrm{mL}$, $1.31 \pm 0.96 \mathrm{U} / \mathrm{mL}$, and $0.96 \pm 0.83 \mathrm{U} / \mathrm{mL}$, respectively; and INS levels were $6.97 \pm 1.00 \mathrm{mIU} / \mathrm{L}, 6.53 \pm 1.27 \mathrm{mIU} / \mathrm{L}$, and $6.27 \pm 1.07 \mathrm{mIU} / \mathrm{L}$, respectively (Tab. 1).

Statistical analysis was performed using the IBM SPSS19 software (SPSS Inc. Chicago, IL). The data obtained were analyzed by one-way ANOVA. The association between FGF21 and other parameters was determined by Pearson's correlation. $\mathrm{P}<0.05$ was considered statistically significant. 
Tab. 1. General clinical data of the study cows

\begin{tabular}{|l|c|c|c|c|}
\hline \multicolumn{1}{|c|}{ Clinical data } & $\begin{array}{c}\text { Q1 } \\
\text { BHBA }(<1.2) \\
(\mathrm{n}=30)\end{array}$ & $\begin{array}{c}\text { Q2 } \\
\text { BHBA }(1.2-1.6) \\
(\mathrm{n}=25)\end{array}$ & $\begin{array}{c}\text { Q3 } \\
\text { BHBA }(>1.6) \\
(\mathrm{n}=35)\end{array}$ & P value \\
\hline Postpartum time (day) & $19.41 \pm 7.69$ & $13.25 \pm 6.51^{*}$ & $18.92 \pm 8.39^{*}$ & 0.033 \\
\hline Age & $3.32 \pm 1.59$ & $4.08 \pm 0.30$ & $4.09 \pm 0.49^{* \#}$ & 0.007 \\
\hline Parities & $2.21 \pm 1.29$ & $2.16 \pm 0.57$ & $2.31 \pm 0.70$ & 0.554 \\
\hline Milk yield $(\mathrm{kg})$ & $26.62 \pm 14.97$ & $22.57 \pm 16.89$ & $26.41 \pm 13.84$ & 0.543 \\
\hline GLU $(\mathrm{mmol} / \mathrm{L})$ & $3.14 \pm 0.71$ & $2.98 \pm 0.59$ & $2.71 \pm 1.26$ & 0.207 \\
\hline NEFA $(\mu \mathrm{mol} / \mathrm{L})$ & $553.99 \pm 285.05$ & $1034.89 \pm 433.75$ & $1186.33 \pm 608.18^{*}$ & 0.001 \\
\hline AST $(\mathrm{mmol} / \mathrm{L})$ & $58.76 \pm 31.63$ & $65.44 \pm 54.38^{*}$ & $19.01 \pm 14.04^{* *}$ & 0.001 \\
\hline ALT $(\mathrm{U} / \mathrm{L})$ & $4.18 \pm 3.11$ & $4.40 \pm 2.34$ & $3.33 \pm 2.31$ & 0.284 \\
\hline TG $(\mathrm{mmol} / \mathrm{L})$ & $0.10 \pm 0.02$ & $0.09 \pm 0.01$ & $0.08 \pm 0.16^{*}$ & 0.017 \\
\hline GI $(\mu \mathrm{mol} / \mathrm{L})$ & $33.14 \pm 15.58$ & $42.07 \pm 19.87$ & $34.43 \pm 15.22$ & 0.193 \\
\hline CKN $(\mathrm{U} / \mathrm{mL})$ & $1.48 \pm 0.76$ & $1.31 \pm 0.96$ & $0.96 \pm 0.83^{*}$ & 0.043 \\
\hline GC $(\mathrm{pg} / \mathrm{mL})$ & $500.99 \pm 94.69$ & $554.66 \pm 123.58$ & $487.09 \pm 85.05$ & 0.073 \\
\hline INS $(\mathrm{mIU} / \mathrm{L})$ & $6.97 \pm 1.00$ & $6.53 \pm 1.27$ & $6.27 \pm 1.07^{*}$ & 0.039 \\
\hline AcAc $(\mu \mathrm{g} / \mathrm{mL})$ & $2.88 \pm 0.46$ & $3.37 \pm 1.16$ & $2.99 \pm 1.08$ & 0.226 \\
\hline GH $(\mathrm{ng} / \mathrm{mL})$ & $5.63 \pm 1.20$ & $5.70 \pm 1.88$ & $5.36 \pm 1.21$ & 0.620 \\
\hline
\end{tabular}

Explanations: * - compared with Q1 P $<0.05$; * compared with Q2 P $<0.05$; BHBA $\beta$-hydroxybutyric acid; GLU - glucose; NEFA - non-esterified fatty acid; AST - aspartate aminotransferase; ALT - alanine aminotransferase; TG - triglyceride; GI - glycerine; CKN - creatine kinase; GC - glucagon; INS - insulin; AcAc - acetoacetate; GH - growth; FGF21 - fibroblast growth factor 21

\section{Results and discussion}

Plasma BHBA levels $>1.20 \mathrm{mmol} / \mathrm{L}$ were the diagnostic criterion for ketosis. Among the 90 cows, 35 cows with clinical symptoms and plasma BHBA levels $>1.60 \mathrm{mmol} / \mathrm{L}$ were diagnosed with CK. Most of the cows in the CK group showed continued depressed appetite, reduced milk production, and weight loss. All had a maximal ketotest reaction and increased free fatty acid concentrations. Twenty-five cows with no clinical symptoms and plasma BHBA levels between 1.20 and 1.60 $\mathrm{mmol} / \mathrm{L}$ were diagnosed with $\mathrm{SK}$, and 30 cows with plasma BHBA levels $<1.20 \mathrm{mmol} / \mathrm{L}$ were healthy controls. Serum FGF21 levels increased with BHBA levels up to $1.60 \mathrm{mmol} / \mathrm{L}$. At BHBA levels $>1.60 \mathrm{mmol} / \mathrm{L}, \mathrm{FGF} 21$ levels decreased. Serum FGF21 levels were $444.17 \pm 119.53 \mathrm{ng} / \mathrm{mL}, 473.62$ $\pm 132.49 \mathrm{ng} / \mathrm{mL}$, and $345.12 \pm 111.96$ $\mathrm{ng} / \mathrm{mL}$ in $\mathrm{NC}$, SK, and CK cows, respectively. Interestingly, when BHBA levels exceeded $1.60 \mathrm{mmol} / \mathrm{L}$, FGF21 decreased compared with SK cows. Therefore, we analyzed the association between serum FGF21 and BHBA levels in Q1-3 (Q1, Q2, and
Q3) cows and Q1-2 (Q1 and Q2) cows.

Based on univariate correlation analyses (Tab. 2), there was a significant positive association between FGF21 and BHBA levels in Q1-2 cows, but not in Q3. Additionally, we analyzed the association between BHBA and other parameters in Q1-3 and Q1-2. BHBA in Q1-3 was negatively associated with $\operatorname{AST}(\mathrm{r}=-0.352, \mathrm{P}=0.002)$, GLU $(r=-0.377, P=0.001)$, ALT $(r=-0.244, P=0.028)$, $\mathrm{TG}(\mathrm{r}=-0.241, \mathrm{P}=0.030)$, and CKN ( $\mathrm{r}=-0.379, \mathrm{P}=0.001)$, and positively associated with NEFA $(\mathrm{r}=0.490, \mathrm{P}=0.001)$ and age $(\mathrm{r}=0.286, \mathrm{P}=0.006)$. BHBA in Q1-2 was negatively associated with postpartum time $(\mathrm{r}=-0.389, \mathrm{P}=0.004)$ and INS $(\mathrm{r}=-0.325, \mathrm{P}=0.028)$ and positively associated with age $(\mathrm{r}=0.158, \mathrm{P}=0.026)$. In contrast, BHBA in Q3 cows with CKN was positively associated only with age $(\mathrm{r}=0.283, \mathrm{P}=0.007)$ and negatively associated with GLU $(\mathrm{r}=-0.399, \mathrm{P}=0.017)$ and $\mathrm{CKN}(\mathrm{r}=-0.503$, $\mathrm{P}=0.002)$.

Tab. 2. Correlations of BHBA with serum FGF21 and other parameters

\begin{tabular}{|c|c|c|c|c|c|c|}
\hline \multirow{2}{*}{ Variables } & \multicolumn{2}{|c|}{ Q1-3 } & \multicolumn{2}{|c|}{ Q1-2 } & \multicolumn{2}{|c|}{ Q3 } \\
\hline & $\mathbf{r}$ & $\mathbf{P}$ & $\mathbf{r}$ & $\mathbf{P}$ & $\mathbf{r}$ & $\mathbf{P}$ \\
\hline Postpartum time & 0.096 & 0.370 & $-0.389 * *$ & 0.004 & 0.099 & 0.349 \\
\hline Age & $0.286^{* *}$ & 0.006 & $0.158^{*}$ & 0.026 & $0.283^{* *}$ & 0.007 \\
\hline Parity & 0.234 & 0.366 & -0.139 & 0.325 & 0.096 & 0.365 \\
\hline Milk yield & 0.017 & 0.872 & -0.067 & 0.637 & 0.079 & 0.499 \\
\hline GLU & $-0.377^{* *}$ & 0.001 & -0.249 & 0.095 & $-0.399 *$ & 0.017 \\
\hline AST & $-0.352^{* *}$ & 0.002 & $0.500^{* *}$ & 0.007 & -0.167 & 0.337 \\
\hline ALT & $-0.244^{*}$ & 0.028 & -0.042 & 0.781 & -0.296 & 0.085 \\
\hline TG & $-0.241^{*}$ & 0.030 & -0.232 & 0.120 & 0.027 & 0.877 \\
\hline GI & -0.050 & 0.657 & $0.339 *$ & 0.021 & -0.167 & 0.336 \\
\hline CKN & $-0.397^{* *}$ & 0.001 & 0.034 & 0.823 & $-0.503^{* *}$ & 0.002 \\
\hline NEFA & $0.490^{* *}$ & 0.001 & $0.542^{* *}$ & 0.001 & 0.25 & 0.147 \\
\hline GC & -0.074 & 0.513 & 0.166 & 0.271 & 0.07 & 0.691 \\
\hline INS & $-0.219 *$ & 0.049 & $-0.325^{*}$ & 0.028 & 0.038 & 0.827 \\
\hline AcAc & 0.048 & 0.669 & $0.297^{*}$ & 0.045 & 0.067 & 0.702 \\
\hline GH & -0.068 & 0.545 & -0.162 & 0.281 & 0.114 & 0.516 \\
\hline FGF21 & 0.049 & 0.063 & $0.647^{* *}$ & 0.005 & 0.009 & 0.960 \\
\hline
\end{tabular}

Explanations: BHBA - $\beta$-hydroxybutyric acid; GLU - glucose; NEFA - non-esterified fatty acid; AST - aspartate aminotransferase; ALT - alanine aminotransferase; TG triglyceride; GI - glycerine; CKN - creatine kinase; GC - glucagon; INS - insulin; AcAc - acetoacetate; GH - growth; FGF21 - fibroblast growth factor 21 
Our correlation analysis showed that BHBA was positively correlated with AcAc. Ketone bodies comprise AcAc, BHBA, and aceton, in which AcAc accounts for $20 \%$ and its activity is unstable $(2,8)$. Ketosis may cause the ketone increase. Therefore, the ketone can be used to diagnose whether the cow suffers from ketosis. Results showed that BHBA was negatively correlated with INS. With the onset of lactation, he rates of gluconeogenesis in the liver are decreased dramatically, and a persistent reduction in blood sugar can make INS secretion decrease. Similar findings have been obtained in this study. In contrast, BHBA were not significantly related to $\mathrm{GC}$ and $\mathrm{GH}$.

This study was the first to establish a quantitative association between FGF21 and BHBA levels in dairy cows with ketosis. The results showed that FGF21 was more closely correlated with BHBA than with other metabolic parameters in dairy cows with SK (1.20 $\mathrm{mmol} / \mathrm{L}<\mathrm{BHBA}<1.60 \mathrm{mmol} / \mathrm{L})$. However, at serum BHBA levels $>1.60 \mathrm{mmol} / \mathrm{L}$, FGF21 tended to decrease. A previous study showed that the energy deficit in dairy cows during early lactation is associated with increased liver FGF21 synthesis and serum FGF21 levels. Mounting evidence suggests that plasma FGF21 in dairy cows similarly increases at parturition when an energy deficit state is induced by feed restriction during late lactation, indicating energy insufficiency as a cause of chronically elevated FGF2 1 in early lactation (19). Similar findings were obtained in this study. Serum levels of ALT, a biomarker of hepatic impairment, increased in dairy cows with CK. Therefore, the reduction in FGF21 in cows with SK may be due to hepatocyte damage resulting from lipotoxicity and hepatic inflammation (20). FGF21 levels in cows with SK increased with increasing BHBA levels, but not in cows with CK. CK cows showed biochemical indexes with elevated ALT concentrations and slightly increased FGF21 levels probably due to hepatic injury. In cows with SK $(1.20 \mathrm{mmol} / \mathrm{L}<\mathrm{BHBA}<1.60$ $\mathrm{mmol} / \mathrm{L}$ ), serum FGF21 was more associated with SK than with other parameters. Therefore, FGF21 may become a novel potential regulator for ketosis. Our study had some limitations. For example, we aimed to determine the association between FGF21 and BHBA in cows from one farm. Future studies should evaluate this association in dairy cows from multiple farms. In conclusion, the results show that FGF21 was closely related with SK in cows. FGF21 may be a promising regulator in the prevention of SK.

\section{References}

1. Bian S. B., Huang K. H.: Survey of Incidence of Hypocalcemia, Ketosis of Dairy Cows in Shanghai Area. Chinese J. of Animal Sci. 2018, 54, 147-150.

2. Bobe G., Young J. W., Beitz D. C.: Invited review: Pathology, etiology, prevention, and treatment of fatty liver in dairy cows. J. of Dairy Sci. 2004, 87, 3105-3124.

3. Cheng X., Zhu B., Jiang F., Fan H.: Serum FGF-21 levels in type 2 diabetic patients. Endocrine Research 2011, 36, 142-148.
4. Coskun T., Bina H. A., Schneider M. A., Dunbar J. D., Hu C. C., Chen Y., Moller D. E., Kharitonenkov A.: FGF21 corrects obesity in mice. Endocrinology 2008, 149, 6018-6027.

5. Duffield T. F., Lissemore K. D., McBride B. W, Leslie K. E.: Impact of hyperketonemia in early lactation dairy cows on health and production. J. of Dairy Sci. 2009, 92, 571-580

6. Fisher F. M., Estall J. L., Adams A. C., Antonellis P. J., Bina H. A., Flier J. S., Kharitonenkov A., Spiegelman B. M., Maratos-Flier E.: Integrated Regulation Of Hepatic Metabolism By Fibroblast Growth Factor 21 (Fgf21) In Vivo. Endocrinology 2011, 152, 2996-3004.

7. Gómezsámano M. Á., Grajalesgómez M., Zuarthvázquez J. M., Navarro-Flores M. F., Martínez-Saavedra M., Juárez-León Ó. A., Morales-García M. G., Enríquez-Estrada V. M., Gómez-Pérez F. J., Cuevas-Ramos D.: Fibroblast growth factor 21 and its novel association with oxidative stress. Redox Biology 2017, 11, 335-341.

8. Heuer C., Luinge H. J., Lutz E. T., Lutz G., Schukken Y. H., van der Maas J. H. H., Wilmink T. M., Noordhuizen.: Determination of acetone in cow milk by Fourier transform infrared spectroscopy for the detection of subclinical ketosis. J. of Dairy Sci. 2001, 84, 575-582.

9. Hove $K .:$ Insulin secretion in lactating cows: responses to glucose infused intravenously in normal, ketonemic, and starved animals. J. of Dairy Sci. 1978, 61, 1407-1413.

10. Jiang J., Qu P., Wei X., Liu Y. F., Li T. Y., Liu Y. X.: Serum hs-CRP, IL-6 and TNF- $\alpha$ levels and their contributions to metabolic syndrome in children. J. of Third Military Medical University 2011, 14, 1530-1534.

11. Kharitonenkov A., Shiyanova T. L., Koester A., Ford A. M., Micanovic R., Galbreath E. J.: Fgf-21 as a novel metabolic regulator. J. of Clinical Investigation $2005,115,1627-1635$.

12. Kliewer S. A., Mangelsdorf D. J., Blackburn G. L.: Fibroblast growth factor 21: from pharmacology to physiology. Am. J. of Clinical Nutrition 2010, 91, $254 \mathrm{~S}$.

13. Kovacevic Z., Cincovic M. R., Stojanovic D.: Influence of ketoprofen application on lipid mobilization, ketogenesis and metabolic status in cows during early lactation. Kafkas Üniv. Vet. Fak. Derg. 2016, 22, 7-12.

14. McArt J. A., Nydam D. V., Oetzel G. R., Overton T. R., Ospina P. A.: Elevated non-esterified fatty acids and beta-hydroxybutyrate and their association with transition dairy cow performance. Vet. J. 2013, 198, 560-570.

15. Ohtsuka H., Koiwa M., Hatsugaya A., Kudo K., Hoshi F., Itoh N., Yokota H., Okada H., Kawamura S.: Relationship between serum TNF activity and insulin resistance in dairy cows affected with naturally occurring fatty liver. J. of Vet. Med. Sci. 2001, 63, 1021-1025.

16. Ospina P. A., Nydam D. V., Stokol T., Overton T. R.: Association between the proportion of sampled transition cows with increased nonesterified fatty acids and $\beta$-hydroxybutyrate and disease incidence, pregnancy rate, and milk production at the herd level. J. of Dairy Sci. 2010, 93, 3595-3601.

17. Patel D. S., Gami B. N., Shah H. N., Parchwani D. N., Haridas N.: Leptin, Adiponectin and its Molar Ratio as a Biomarker in the Diagnosis of Metabolic Syndrome. Indian J. of Physiology \& Pharmacology 2015, 59, 290-297.

18. Potthoff M. J., Inagaki T., Satapati S., Ding X., He T., Goetz R., Mohammadi M., Finck B. N., Mangelsdorf D. J., Kliewer S. A., Burgess S. C.: FGF21 induces PGC-1alpha and regulates carbohydrate and fatty acid metabolism during the adaptive starvation response. Proc. of the National Academy of Sciences 2009, 106, 10853-10858.

19. Schoenberg K. M., Giesy S. L., Harvatine K. J., Waldron M. R., Cheng C., Kharitonenkov A., Boisclair Y. R.: Plasma FGF21 is elevated by the intense lipid mobilization of lactation. Endocrinology 2011, 152, 4652-4661.

20. Yan H., Xia M., Chang X., Xu Q., Bian H., Zeng M., Rao S., Yao X., Tu Y., Jia $W$., Gao X.: Circulating Fibroblast Growth Factor 21 Levels Are Closely Associated with Hepatic Fat Content: A Cross-Sectional Study 2011, 6, 24895.

Corresponding author: Dr. Chuang Xu, College of Animal Science and Veterinary Medicine, Heilongjiang Bayi Agricultural University, Daqing High-tech Industrial Development Zone, Daqing 163319, PR China; e-mail: xuchuang7175@163.com 